\title{
MOVIMIENTOS SOCIALES Y CAMBIO SOCIAL ¿Una lógica o varias lógicas de acción colectiva?*
}

\author{
SALVADOR AGUILAR \\ Universidad de Barcelona
}

PALABRAS CLAVE ADICIONALES

Articulación de intereses, Acción colectiva, Teoría sociológica, Estructura social.

\author{
ADDITIONAL KEYWORDS \\ Organized Interests, Collective Action, \\ Social Structure, Social Theory.
}

RESUMEN. Este trabajo pone en cuestión el supuesto, muy extendido en la teoría sociológica, de que los movimientos sociales son los agentes por excelencia del cambio social. Aquí se propone una reformulación conceptual en el campo del estudio de la acción colectiva (y en particular de la acción colectiva informal, campo donde se insertan los movimientos). Para ello, se da, en primer lugar, entrada a la noción de "acción colectiva de masas", como alternativa más precisa conceptualmente, y también valorativamente más neutra, que la de "turba" (mob) o "muchedumbre" (crowd) utilizada por historiadores sociales y sociólogos de la historia. En segundo lugar, se hace un balance de lo que la teoria sociológica postolsoniana de la acción ha aportado al conocimiento del fenómeno de la acción colectiva. El trabajo pretende mostrar que esta aportación es ya, hoy, sustantiva, y que, contrariamente a supuestos heredados, permite concluir inequívocamente que no hay una lógica unitaria, sino plural de la acción colectiva.

E-mail: saguilar@riscd2.eco.ub.es

- Agradezco los comentarios de mis colegas y amigos Xavier Godàs y Tomàs Herreros (Universidad de Barcelona, Departamento de Teoría Sociológica), que me han permitido mejorar la versión final. Agradezco finalmente los comentarios de mis alumnos y alumnas de la Licenciatura de Sociología de la UB en las asignaturas de Estructura y Cambio de las Sociedades y Movimientos Sociales. Agradezco finalmente a Eric Hobsbawm la continuada y poderosa influencia que ha tenido, con sus publicaciones, sobre mi trayectoria intelectual y, en concreto, sobre el tema que desarrolla el presente artículo; a pesar de que éste cuestiona algunas de las tesis de Hobsbawm, lo hace con el mayor de los respetos y reconociendo la enorme deuda intelectual que el autor, y seguramente toda una generación de sociólogos e historiadores sociales, mantiene con el maestro inglés.

Revista Internacional de Sociología (RIS)

Tercera Época, ${ }^{\circ}$ 30, Septiembre-Diciembre, 2001, pp. 29-62. 
ABSTRACT. This article questions an idea that tends to be taken for granted by many social theorists, namely, the supposed status of social movements as the most oustanding agents of social change. The article suggests a conceptual reformulation regarding research on collective action; more specifically, that reformulation regards the study of informal collective action, a category which includes social movements. In order to do so, firstly, the notion of "collective mass action" is proposed as a conceptually more precise (and normatively more neutral) alternative to established concepts as used by social historians and sociologists of history, such as "mob" or "crowd". Secondly, the contribution of post-Olsonian sociological theory of action to our current knowledge of collective action is assessed. The article intends to demonstrate that a substantial such contribution indeed exists and that it leads to a clear conclusion, namely: contrary to received wisdom, which assumes that collective action is governed by one unitarian logic of action, there actually is a plurality of logics of collective action.

\section{INTRODUCCIÓN}

Parece fuera de duda que las ciencias sociales no disponen de una teoría estándar del conflicto social, es decir, una teoría probada que exprese el consenso mayoritario de la profesión (o conocimiento adquirido) en lo que se refiere a ese fenómeno. Y específicamente, la importante relación entre conflicto y cambio social exhibe numerosos aspectos sin explicaciones sólidas o con explicaciones claramente insatisfactorias. Aquí nos centraremos en una dimensión de esa relación, como sugiere el título del trabajo. Partiremos de una posición que surge prontamente al revisar la literatura especializada en la sociología del conflicto y de la acción colectiva, a saber: la insistencia de no pocos investigadores en considerar como algo obvio una relación entre el conflicto y el cambio social expresable de esta manera:

\section{CONFLICTO (-> ACCION COLECTIVA -> MOVIMIENTOS SOCIALES) -> CAMBIO}

De esta posición cabe deducir dos proposiciones: i) que el conflicto es un factor desencadenante universal del cambio social y que debe operacionalizarse como acción colectiva; y ii) que una dimensión de ésta, los movimientos sociales, son los agentes por excelencia del cambio social y siguen una pauta fundamentalmente unitaria (es decir, organizada alrededor de una única lógica de la acción colectiva). La primera proposición no se ajusta a la realidad y ha sido tratada en otro lugar (Aguilar, 2001: cap. 6). La segunda es el objeto de este trabajo y su tratamiento, a continuación, se desarrolla en tres apartados.

En el primero examinamos el problema al que da lugar la segunda proposición aludida una vez se elaboran sus implicaciones. El problema se expresa en ciertos "enigmas" (desajustes inexplicables entre lo que propone la teoría y lo que se observa empíricamente) y se resume en una pregunta teórica general: ¿hay una lógica de la acción colectiva o existen lógicas plurales?. M. Olson (1965) parece establecer en su obra clásica que sólo hay una lógica, universal, de la 
acción colectiva (una posición que en general, ha sido interpretada así por sus principales continuadores y comentaristas de su obra). A mi entender, sin embargo, éste es un caso, entre otros muy celebrados (por ejemplo, los estudios de D. Bell de 1967 y 1976), de poco feliz culminación -y con un título desafortunado- de una gran obra.

$\mathrm{Y}$ esto es así porque una lectura atenta del texto clásico de $\mathrm{M}$. Olson deja lugar a pocas dudas. En efecto, la lógica unitaria de acción colectiva sólo rige para un determinado ámbito (las asociaciones económicas) y en una variante perfectamente acotada del mismo (los actores tratados por la teoría olsoniana son organizaciones formales, de gran dimensión y productoras de bienes públicos), fuera de la cual la teoría se transforma, caso de intentar aplicarla, en una ocurrencia'. Asimismo, y más específicamente, los movimientos sociales y fenómenos conexos (los "movimientos de masas"), no son, según señala el mismo M. Olson (1965:161-162) ${ }^{2}$, fenómenos que la teoría que expone se proponga explicar o esté preparada para ello. A pesar de lo cual, irónica y sorprendentemente, no pocos sociólogos de los movimientos sociales quedaron fascinados con una lógica que, por decirlo así, no era de su competencia, e incorporaron erróneamente a sus planteamientos la discusión con la lógica olsoniana, frecuentemente con propósitos supuestamente críticos ${ }^{3}$.

¿Por qué y de qué manera es importante la pregunta teórica anterior, sobre si hay una o varias lógicas de la acción colectiva?. Una respuesta sólidamente fundamentada a esta pregunta es importante porque, si lo que prima empíricamente son las lógicas plurales, entonces queda invalidada una idea muy extendida en el seno de la teoría social. Esta idea consiste en proponer, como

\footnotetext{
' Paradójicamente, practicada por el propio $\mathrm{M}$. Olson en los primeros años noventa, sobre todo en sus colaboraciones periodísticas sobre Sadam (Wall Street Journal 22.II.1991) y un trabajo sobre la sociedad de modelo soviético (1990). Véase también M. Olson (2000). Así, los famosos "incentivos selectivos" olsonianos han sido "descubiertos" por investigadores posteriores en situaciones de lo más extravagante (sin relación alguna con las estipulaciones de la teoría original $y$, a veces, sin relación alguna con el sentido de realidad).

${ }^{2}$ Véase también al respecto el perceptivo balance que hace M. I. Lichbach (1998:10-11).

${ }^{3}$ Uno de los mejores estudiosos actuales de los movimientos lo ha señalado sin ambages; véase S. Tarrow (1997: cap. 1, nota 18). Otras excepciones inteligentes son las de E. Neveu (1996) y la de G. Marwell y P. Oliver (1984:4), quienes dicen que "la mayoría de los estudiosos de los movimientos sencillamente se limitan a citar a Olson cuando se trata de problemas de la acción colectiva. Sólo unos pocos ... han desarrollado modelos formales para situaciones particulares de acción colectiva y han considerado sus implicaciones para ciertos problemas de movilización". A estas precisiones sobre la obra de Olson deberíamos añadir otra, de carácter general, señalada por D. McAdam, S. Tarrow y Ch. Tilly (1997:147): “... a pesar de que la denominó teoria de la 'acción colectiva', M. Olson tenía poco que decir más allá del nivel individual de motivación y agregación”; el importante trabajo de M. Olson, por tanto, trata sobre todo, no de la acción colectiva, sino de la acción individual en contextos de reivindicación colectiva.
} 
se ha recordado antes, que los movimientos sociales son los agentes del cambio social, afirmación que tácitamente supone proponer también que i) hay una sola lógica de la acción colectiva (unitaria, "la" de los movimientos) que rige en esa zona de la acción social; y ii) que la relación entre movimientos y cambio social es del tipo MMSS -> CS (los movimientos son agentes causales o propulsores del cambio social). Esta idea, por ejemplo, impregna el importante estudio de P. Sztompka (1995) y aparece con claridad en el propio encabezamiento del capítulo 19 de esa obra ("Los movimientos sociales como fuerzas de cambio") 4 . La idea, sin embargo, es equívoca y probablemente falsa. Nuestra tarea aquí consistirá en mostrar lo siguiente.

En primer lugar, que el cambio social es multicausal, siendo los movimientos sociales uno más de sus factores desencadenantes (cuando es el caso). En segundo lugar, que sabemos bastante sobre cómo el cambio impacta sobre los movimientos sociales, pero mucho menos sobre cómo los movimientos impactan sobre (favorecen o dificultan) el cambio social (Tilly, 1998:37). En tercer lugar, que los movimientos sociales constituyen lo que podríamos denominar una variante de "institución de acción colectiva", según veremos más abajo,

\footnotetext{
${ }^{4}$ Los ejemplos podrian fácilmente multiplicarse. Debo precisar, sin embargo, que en este como en otros casos el problema procede en parte de una errónea conceptualización de "movimiento social"; P. Sztompka abre el capítulo 19 (p. 303) con un párrafo descriptivo donde se identifican como movimientos lo que en realidad son acciones colectivas de masas ("multitudes en las plazas de las ciudades protestando contra un gobierno opresivo"), acciones colectivas desencadenadas por sindicatos ("los mineros británicos del carbón en huelga"), conflictos religiosos ("musulmanes atacando cristianos o viceversa") o actos de guerra ("serbios combatiendo con bosnios").

${ }^{5}$ Un problema de la teoría social moderna consiste en denominar correctamente las entidades (formatos institucionales) utilizadas para promover y facilitar la acción colectiva de los individuos. Convencionalmente, se usa el término de "grupo de interés", a nuestro entender equívoco, con fuerte carga valorativa implícita y que, en realidad, sólo cubre a una parte de los entes institucionales afectados (por ejemplo, es inadecuado precisamente para los movimientos sociales). Una denominación reciente mucho más adecuada -"organizaciones de acción colectiva" (OAC)corresponde a D. Knoke (1990:7), que las define así: asociaciones dotadas de organización formal; que buscan soluciones no de mercado a problemas individuales y colectivos; con una membresía que tiene carácter formal y voluntario; y que se guían por procedimientos democráticos para establecer las decisiones relativas a las políticas que siguen. Por lo que se refiere a los movimientos, sin embargo, D. Knoke sólo considera como OAC a las OMS (organizaciones de movimiento social, como los sindicatos en relación con el movimiento obrero, por ejemplo) y a los aparatos organizacionales de las asociaciones de que se dotan los movimientos específicos. A nuestro entender, no obstante, los movimientos mismos (sean generales o específicos) constituyen formatos institucionales que facilitan y promueven un tipo distintivo de acción colectiva (lo mismo sucede con otra variante, próxima, que en este artículo denominamos "acción colectiva de masas"). Por ello, en un trabajo anterior (Aguilar, 1994), modifiqué ligeramente la noción de OAC que propone D. Knoke para incluir no sólo a organizaciones formales sino también a "cuasi-organizaciones, es
} 
entre otras; $y$, como tales, pueden ser tanto fuerzas de cambio como fuerzas de resistencia al cambio ${ }^{6}$ (casos paradigmáticos de esta última tendencia son, por ejemplo, la Vendée, en $1793^{7}$, ciertas acciones de las "turbas" urbanas en no pocas grandes ciudades preindustriales [Hobsbawm, 1959:117-119] o la base social del pinochetismo contemporáneo). Y en cuarto lugar, que la acción colectiva sigue lógicas múltiples, cosa que, según se intentará mostrar, es cierto para el conjunto de fenómenos sociales que englobamos bajo ese rótulo, pero también, y particularmente, para el caso de los movimientos sociales.

Los movimientos sociales, una variante institucional entre otras de la acción colectiva, exhiben como mínimo las siguientes lógicas internas de acción: a) la que diferencia los movimientos sociales propiamente dichos de lo que denominaremos "acciones colectivas de masas" (por ejemplo, la "revuelta social" de diciembre de 1995 en Francia), que son de la misma "familia" fenoménica, pero presentan una lógica propia y diferenciada; b) la que diferencia tipos estructurales de movimientos sociales, a partir de la distinción clásica de $\mathrm{H}$. Blumer (1969) entre movimientos generales, específicos y expresivos, y c) la que corresponde a las oleadas cronológicas de los movimientos sociales (los tipos históricos), de los que distinguiremos cinco tipos mayores: "primitivos", "clásicos", "nuevos", "novísimos" y "antisistémicos en la periferia contemporánea".

Encontrar respuestas satisfactorias a la pregunta teórica sobre la lógica (única o plural) de la acción colectiva tiene además una relevancia metodológica. Por un lado, en efecto, permitiría que los modelos sobre la acción colectiva ganaran en precisión conforme pasamos de macro a microsituaciones (de un modelo único para cualquier variante de acción colectiva, a otro para movimientos, otro

decir, entidades asociativas que desarrollan intermitentemente aparatos de organización formal" (1994:270). Posteriormente, he llegado a la conclusión que la palabra "organización de acción colectiva (OAC)" induce a confusión, aun con la modificación aludida, al dificultar la asociación mental de movimientos sociales o acciones colectivas de masas con ese concepto; por ello, propongo denominar como "instituciones de acción colectiva" (IAC) al conjunto de entes que con esa finalidad pueden identificarse en una sociedad moderna (véase en el diagrama 1 la identificación de tales entes).

"La relativa frecuencia de movimientos sociales de orientación conservadora y reaccionaria estaba ya bien establecida en la etapa clásica de la sociologia de la acción informal; véase al respecto el conocido texto de R. Turner y L. Killian (1972; primera edición de 1957).

'Véase el estudio clásico de Ch. Tilly (1967).

"Estos tipos históricos son expresión, en realidad, de cambios de "registro" (Tilly), de modificaciones sustantivas en la forma de organización social y de las consiguientes modificaciones de las pautas del conflicto social; como explicó gráficamente M. Bloch: "la rebelión campesina es tan inseparable del régimen señorial como la huelga de la gran empresa capitalista" (citado en Tilly, 1969:5). Algo similar puede decirse de los movimientos sociales, que no tienen, por tanto, una naturaleza única y transhistórica. 
para asociaciones económicas, otro para sindicatos, etcétera). Por otro lado, derivadamente, permitiría, por así decirlo, estudiar regionalmente la relación entre cambio social y cada una de las instituciones de acción colectiva, entre ellas los movimientos sociales?.

\section{ALGUNAS CUESTIONES NO EXPLICADAS}

Hay una ortodoxia dominante en el terreno de la teoría social que intenta dar cuenta de los fenómenos de la acción colectiva en una gran variedad de contextos. Este consenso teórico, predominante en la vida académica, gira alrededor de dos grandes tradiciones: la de los grupos de interés y la de la lógica olsoniana de la acción colectiva y sus derivaciones ${ }^{10}$. No obstầnte, esta ortodoxia dominante, con independencia de sus logros reales (y también de sus limitaciones y déficits, de los que no nos ocupamos aquí), deja sin explicar numerosos fenómenos de gran envergadura en la historia contemporánea de la acción colectiva, de los que destacaríamos tres: la oleada de movilizaciones de los años sesenta del siglo XX en la mayor parte de los países occidentales

9 Antes de entrar en el meollo de la respuesta a nuestra pregunta, parece conveniente una pequeña aclaración conceptual sobre la expresión "lógica de la acción colectiva". ¿Cuál es su significado preciso?. En términos elementales, esta noción hace referencia a aquello que explica por qué un actor hace lo que hace, y lo que tenderá a hacer atendiendo al comportamiento de ciertas variables clave (los parámetros de la acción) que exhibe y que configuran en gran parte la gama de conductas posibles que desarrollará el actor. A su vez, definimos la noción de "acción colectiva" como una acción de grupo concertada e intencional, vinculada a una lógica reivindicativa, derivada a su vez de intereses colectivos, y que se manifiesta de dos maneras principales: agregando intereses (creando redes asociativas y, en el límite, organización) y llevando a cabo exhibiciones de fuerza colectiva en forma de actos de protesta o de presión. Cualquiera de estas dos actividades o manifestaciones (asociación y protesta), y las dos combinadas, derivan de un conjunto de parámetros (estructurales, relacionales) por los que se rigen principalmente los sujetos de la actividad asociativa y de protesta y que: (a) orientan y hasta cierto punto determinan su comportamiento y las divergencias entre el comportamiento de diferentes sujetos; y (b) son imprescindibles para su correcta observación y eventual comprensión. Establecer cuáles sean estos parámetros equivale a identificar la "lógica de la acción colectiva" de un actor social.

${ }^{10}$ Estas dos tradiciones no siempre van de la mano. P. Lange (1977 y 1982) opina, con razón, que la obra de $\mathrm{M}$. Olson es una carga de profundidad contra la versión ingenua de la "teoría de los grupos" por lo que se refiere a la actividad política; lo que $\mathrm{M}$. Olson plantea de fondo es que esta actividad es, frecuentemente, no escogida, sino inducida (por organizaciones que utilizan incentivos), y que el "efecto multiplicador" que la "teoría de los grupos" espera de la contribución natural de los individuos a la acción colectiva no se corresponde necesariamente con la observación empírica. Por eso, con sentido del humor, M.I. Lichbach (1998:12) ha tachado las proposiciones olsonianas de "Ley General de la Inacción Colectiva". 
(movilizaciones aproximadamente coincidentes con la aparición de la obra clásica de $\mathrm{M}$. Olson y que, además, contribuyeron a impulsar profundas transformaciones societarias en esos países); la oleada reciente de la coyuntura fuerte de 1989 (las movilizaciones en los países del Este que preludian las salidas de la dictadura en esas sociedades); y el ciclo, al parecer carente de pauta, de grandes movilizaciones de masas que se producen en España entre 1986 y 1997 (desde la movilización sobre la OTAN y el referéndum convocado por el gobierno del PSOE, hasta las manifestaciones contra ETA por el asesinato de Miguel A. Blanco) y en Francia a mediados de los años noventa.

La primera cuestión no explicada (o enigma) y que intentaremos descifrar aquí es la siguiente: ¿cómo es posible que el consenso teórico al que hemos aludido haya sido incapaz de ofrecer explicaciones satisfactorias sobre fenómenos de acción colectiva de la importancia de los mencionados ${ }^{11}$ ? Y si esto es así, ¿qué modificaciones deben introducirse en la teoría para encontrar tales explicaciones?; ¿cuál es el arsenal teórico al que la sociología puede acudir para abordarlas?. Nuestra respuesta, en síntesis, es que, por motivos diferentes, ni la tradición olsoniana ni la de los grupos de interés están diseñadas para comprender fenómenos ubicados dentro de lo que conocemos como "acción colectiva informal".

La segunda cuestión no explicada es un caso particular del anterior: la coyuntura de cambio societario de 1989 en el Este europeo y el papel jugado en ella por los movimientos sociales. Veamos lo que dice un cualificado observador del fenómeno, P. Sztompka (1995:335):

\footnotetext{
${ }^{11}$ Un aspecto derivado de la cuestión, pero en el que no entraremos aquí, es averiguar en qué se funda la legitimidad intelectual de unas tradiciones teóricas tan poco eficientes. Digamos simplemente que un divertido -pero durísimo y seguramente algo injusto- argumento en esa dirección es el avanzado por A. Hirschman (1985:78-79): "Olson proclamaba la imposibilidad de la acción colectiva por parte de grandes grupos (de manera similar a la proclamación de Daniel Bell sobre el 'final de la ideología') en el momento exacto en que el mundo occidental estaba a punto de quedar sumergido en una oleada sin precedentes de movimientos, marchas, protestas, huelgas e ideologías públicos. (...). El éxito del libro de Olson se debe en parte a que fue contradicho por la evolución de los acontecimientos subsiguientes. Una vez que éstos habían completado su recorrido sin mayores contratiempos, las muchas personas que los encontraron profundamente inquietantes pudieron retornar a las páginas de La lógica de la acción colectiva y encontrar en ellas razones sólidas y tranquilizadoras sobre por qué esas acciones colectivas de los sesenta, para empezar, nunca debieron ocurrir, tal vez fueron menos reales de lo que parecieron o era muy improbable su reaparición. Por tanto, el libro no sufrió al ser contradicho por los acontecimientos, sino que, al contrario, se benefició de ello y se convirtió en un gran éxito entre aquéllos que evaluaron esos acontecimientos como intolerables y totalmente aberrantes. ¡De esta manera, en las ciencias sociales, las falsas profecías pueden constituirse en piedra angular de la fama y la reputación!".
} 
"La mayoría de los autores [estudiosos del fenómeno de la revolución] parecen creer que las revoluciones implican necesariamente violencia y coacción. Este es el único punto rebatible a la vista de la evidencia histórica de movimientos "revolucionarios" básicamente no violentos y sorprendentemente eficaces y de largo alcance, como el gandhismo en la India, o movimientos sociales recientes en Europa central y del este, que forzaron el colapso del comunismo (por ejemplo, la "revolución pacifica" de la Solidaridad polaca, o la "revolución de terciopelo" en Checoslovaquia). Los observadores contemporáneos no han vacilado al denominar a estos últimos casos como revoluciones. Consideremos la opinión de un eminente historiador británico: "Las revoluciones de 1989 fueron revoluciones reales: revueltas populares ante las que los gobiernos armados, uno tras otro, sucumbieron; fue la recuperación por las naciones de su perdida libertad" (Trevor-Roper). Podría añadirse que, aunque en el caso de las revoluciones anticomunistas (con la triste excepción de Rumanía) la violencia efectiva estuvo ausente, la amenaza potencial de violencia estaba implicada con claridad en lo masivo de la movilización y en el nivel de compromiso o excitación emocional de las masas. Fue bajo la presión de esa amenaza persistente de fuerza como se produjo la abdicación de las autoridades comunistas. [La cursiva es nuestra]"

P. Sztompka sintetiza en este párrafo tanto su propia concepción de las movilizaciones a las que alude, como la de numerosos observadores occidentales (la mayoría, periodistas, pero también no pocos científicos sociales). El enigma es el siguiente: he aquí un actor social singularísimo, capaz de derrocar nada menos que a poderosos y extremadamente coercitivos sistemas sociales (el modelo soviético estalinista de organización social) y desencadenar transformaciones sociales de gran magnitud, que, sin embargo, desaparece a continuación sin dejar rastro ${ }^{12}$. Según nuestro punto de vista, y en marcado desacuerdo con el

\footnotetext{
${ }^{12}$ Obviamente, dejamos de lado el caso de Solidarnosc, que de ninguna manera desaparece sin dejar huella; pero tampoco se trata exactamente de un movimiento social, aunque opera en el seno de uno. En la presentación que sigue nos centramos en las grandes movilizaciones efimeras que presidieron el cambio de régimen en algunos paises del Este en la coyuntura de 1989; por ejemplo, las de Leipzig (La Vanguardia, 10.X.1989, p. 4) y Berlin Este (La Vanguardia, 5.XI.1989, p. 3).

${ }^{13}$ Ciertos estudiosos (Dahrendorf, Garton Ash) tienen dudas sobre lo acaecido y se inventan la palabreja "refolución" (reforma desde arriba más revolución desde abajo) para designarlo. Pero la mayoria de observadores no tiene dudas: la revolución comunista ha sido interrumpida ( $y$ ha colapsado) por efecto de una revuelta popular de orientación emancipatoria. Un experto como $\mathrm{R}$. Sakwa (1999:87) opta por una sugestiva interpretación intermedia: "La era del revolucionarismo de la Ilustración finaliza con una revolución. La paradoja es deliberada: las revoluciones de 1989-91 fueron revoluciones antirrevolucionarias", en el sentido de que ponen fin tanto a un ciclo revolucionario (el que empieza en 1917) como a una época y "su forma de entender la politica y los procesos de cambio social".
} 
dictamen de P. Sztompka: ni esos procesos de presión para el cambio fueron "revoluciones"13 (aunque este aspecto de la cuestión no nos interesa directamente aquí) ni esas movilizaciones de masas, en términos generales, procedían de actores que se pudieran asociar con lo que habitualmente denominamos "movimientos sociales".

Tanto en uno como en otro caso, la consideración de nuestros enigmas o cuestiones no explicadas nos permitirá poner de relieve la importancia de la teoría y de la conceptualización correcta para afrontar el análisis de fenómenos novedosos como los citados. En el segundo caso, poniendo de relieve que, aunque se parecen o son de la misma familia, los actores colectivos que operan en la caída de los regímenes estalinistas no son movimientos sociales, careciendo de sentido, en consecuencia, tratarlos y analizarlos como si lo fueran y siguieran la lógica de la acción colectiva que asignamos habitualmente a aquéllos. En el primer caso, y situados ya en un plano más general, poniendo de relieve la falacia de postular para ellos una única lógica de la acción colectiva ${ }^{14}$. Por varios motivos, que argumentaremos, lo que podemos observar empíricamente son lógicas plurales de acción colectiva. Como parece natural, una de las habilidades fundamentales de un investigador debe consistir en identificar correctamente la variante o combinación de variantes a la que pertenece el fenómeno que observa y que pretende explicar (derivando así con propiedad, la lógica de la acción colectiva que nos da la clave, no sólo para investigar, sino para hacer las preguntas relevantes). Como veremos, el consenso ortodoxo sobre la base de la teoría olsoniana hace referencia, en realidad, no a una única y universal lógica de la acción colectiva, sino a una variante particular de ésta, la de las asociaciones económicas ${ }^{15}$.

\footnotetext{
${ }^{14}$ Un problema éste que, epistemológicamente, es una variante de algo más general, bien captado por A. Melucci (1996:14-15,4): Todavía persiste una ingenua presuposición epistemológica según la cual "la unidad fáctica del fenómeno, tal como la percibe o cree presenciar el observador, existe realmente. La proximidad espacial y temporal de formas concomitantes de conducta individual y de grupo es elevada desde el nivel fenomenológico al conceptual concediéndosele, por tanto, peso ontológico y homogeneidad cualitativa: la realidad colectiva, como si dijéramos, existe como una cosa unificada". "Los movimientos no son entidades que se muevan con la unidad de metas que les atribuyen los ideólogos. Los movimientos son sistemas de acción".

${ }^{15}$ Algo que ha visto muy bien, en época reciente, S. Tarrow (1997:43-44): "Al parecer, a McCarthy y Zald no les preocupó el hecho de que Olson no estuviera fundamentalmente interesado en los movimientos sociales, sino en los grupos de interés. De hecho, Olson habia generalizado a partir de una categoría aún más limitada: las asociaciones económicas. En este terreno, su versión de los problemas de la acción colectiva es claramente válida por tres razones. La primera es que en las asociaciones económicas la medida del éxito es la utilidad marginal, claramente definida y generalmente comprendida. En segundo lugar, para tales organizaciones es crucial qué proporción del grupo participa en la acción colectiva, ya que si sus líderes no son respaldados por un número suficiente de miembros, sus oponentes carecen de motivos para tomarles en serio. Finalmente,
} 


\section{LÓGICAS PLURALES DE LA ACCIÓN COLECTIVA}

Sabemos que las expresiones empíricas del conflicto social son innumerables. Ch. Tilly (1998:30), bajo la denominación de "conflicto político", las describe acertadamente así:

"El conflicto político incluye todas las ocasiones 1) en las que algún grupo de personas realiza reivindicaciones colectivas públicas visibles sobre otros actores (reivindicaciones que si se cumpliesen afectarían los intereses de estos últimos) y 2) en las que al menos una de las partes afectadas por reivindicaciones, incluyendo terceras partes, es un gobierno. Por lo tanto, el conflicto político abarca revoluciones, rebeliones, guerras, conflictos étnicos, movimientos sociales, genocidio, campañas electorales, la mayoría de las huelgas y cierres patronales, parodias públicas, incautaciones colectivas de mercancías, y muchas otras formas de interacción".

Si consideramos un país medio contemporáneo de la OCDE, la noción de acción colectiva sirve para dar cuenta de únicamente una parte de esta amplia variabilidad fenoménica del conflicto político ${ }^{16}$. Lo que nos interesa establecer aquí es si la lógica subyacente a los fenómenos aludidos por Ch. Tilly y que pertenecen a esta categoría de acción colectiva es la misma. Para ello, i) nos interrogaremos sobre las variantes tipológicas de la acción colectiva y su correspondiente expresión en actores institucionales diversos (las "instituciones de acción colectiva" antes aludidas); y ii) consideraremos el conocimiento sociológico sólido acumulado sobre tales variantes (de manera que, en su caso, se puedan establecer varias lógicas de la acción colectiva derivadas de ese conocimiento). Mi respuesta a esta interrogante trata de ampliar una conceptualización propuesta por Ph. Schmitter y W. Streeck (1981) y queda sintetizada en el diagrama que sigue (modificado a partir de Aguilar, 1994: 202), y que será objeto de comentario a continuación (Diagrama 1).

estas asociaciones están organizadas de modo transparente y cuentan con líderes fácilmente identificables que intentan movilizar a miembros formalmente asociados en una acción colectiva en torno a una serie finita de objetivos. Pero, teóricamente, ninguno de estos criterios es aplicable a los movimientos sociales".

${ }^{16}$ Hay otras tres categorías teóricas para pensar el conflicto político en un régimen poliárquico (Aguilar, 2001: cap. 6): la "política institucional" (que configuran la "política de los intereses" o interacción permanente entre intereses organizados y entre éstos y el Estado; y la "política partidaria" o interacción entre los partidos políticos y entre estos y el Estado), y lo que T. R. Gurr (1969), en formulación clásica, ha definido correctamente como "conspiración" y "guerra interna". Aunque ahora no nos interese desarrollar la idea, obsérvese que, procediendo a partir de estas nociones teóricas formales (todas ellas respaldadas por auténticas teorías, en cuyo seno cobran sentido aquéllas, y respondiendo a lógicas distintivas), el amplio abanico de fenómenos enunciado por $\mathrm{Ch}$. Tilly en su cita anterior se distribuye conceptualmente sin dificultad entre las cuatro categorías del conflicto social enunciadas. Para una clasificación alternativa de las dimensiones del conflicto social, véase A. Melucci (1996). 


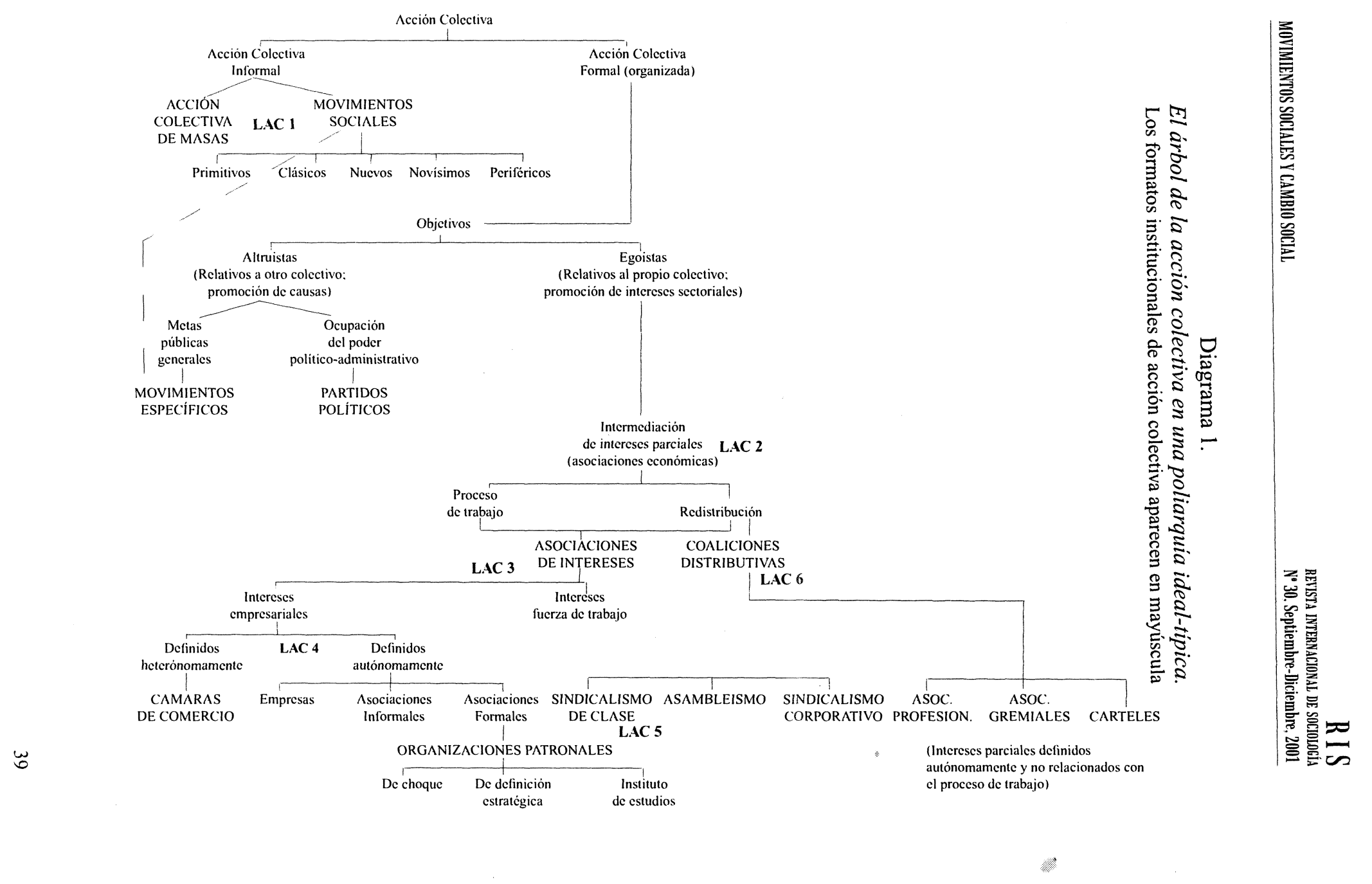


R I S

En el contexto de una sociedad de tipo medio de la OCDE, la acción política de los individuos en pos de sus intereses y pasiones ("causas") encuentra contemporáneamente cada vez menos un cauce viable (eficiente) en la acción individual ${ }^{17}$ : los individuos que viven en sociedades complejas se ven progresivamente empujados a la acción colectiva. Esta acción colectiva, nuestro objeto de reflexión aquí, puede ser informal o formal (dotada de organización).

$\mathrm{La}$ "acción colectiva informal" tiene diversas variantes principales. Estructuralmente, exhibe tres formas: la acción colectiva de masas, los movimientos sociales (generales) y los movimientos específicos (o monográficos o issue-movements, es decir, orientados a objetivos restringidos, relativamente efímeros, que representan intereses muy amplios y que se dotan de alguna asociación-organización estable ${ }^{18}$ ). La "acción colectiva informal" presenta una lógica peculiar de la acción colectiva ( $\mathrm{LAC} 1$, en el diagrama $\mathrm{n}^{\circ} 1$ ) perfectamente diferenciada de la característica de otros entes o formatos institucionales (que aparecen en dicho diagrama) $)^{19}$. Y la sociología actual conoce razonablemente bien su dinámica gracias entre otros, pero sobre todo, a los estudios de $\mathrm{Ch}$. Tilly (1978 y 1995); M. Giugni, D. McAdam y Charles Tilly (eds.) (1998) y S. Tarrow (1995, 1997 y 1998). Sin embargo, como exploramos en el siguiente epígrafe, la sociología de los movimientos sociales puede establecer ya diferenciaciones internas de esta lógica sectorial (de la acción informal): por un lado, al diferenciar entre dos tipos estructurales notablemente divergentes del fenómeno (la acción colectiva de masas y los movimientos sociales); y por otro, al distinguir lógicas de acción colectiva divergentes en los tipos (estructurales, históricos) de los movimientos sociales (véase más abajo).

Por su parte, la "acción colectiva formal" significa que ciertos sujetos de la acción están en condiciones y buscan dotarse de organización formal (con lo cual la pauta de acción colectiva forzosamente diverge del caso anterior). Una parte de los entes institucionales que genera esta pauta persiguen principalmente objetivos que afectan a sectores sociales que exceden (o incluso, no coinciden con) la base social más próxima al ente: o bien persiguen intereses muy amplios, cuasi-universales y se orientan a promocionar "causas" que benefician a mucha

\footnotetext{
${ }^{17}$ Como bien señalaron M. Pérez Yruela y S. Giner (1988:22) al remarcar la tendencia de las sociedades modernas a la "corporatización", entendida como "la presencia creciente de grandes organizaciones que mediatizan las formas de estructuración y conflicto y generan nuevos modelos de interacción entre el Estado y la sociedad civil" (entre ellos, "la primacía de la acción colectiva sobre la individual para la defensa de los intereses").

${ }^{18}$ Esta es la razón por la que figuran en el diagrama $n^{\circ} 1$ como parte de la acción colectiva formal, aunque conectados (línea discontinua) a los movimientos sociales, puesto que son una variante de éstos.
} 
gente (con frecuencia, los movimientos específicos); o bien se orientan a la ocupación del poder político-administrativo (los partidos), lo cual, teniendo en cuenta el fenómeno contemporáneo del catch-all party (Kirchheimer), separa a los partidos políticos de aquellas instituciones de acción colectiva que representan y defienden exclusivamente intereses de su base social más próxima ${ }^{20}$ (intereses sectoriales), siendo las asociaciones económicas (patronales, sindicatos, colegios profesionales, etc.) su expresión más acreditada. El conocimiento que poseemos de la lógica de acción que distingue a estas asociaciones es sobre todo deudor del trabajo clásico de $\mathrm{M}$. Olson ya citado (1965; véase la nota 15 anterior) y del torrente de investigación que ha generado (Lichbach, 1998: cap.1). La lógica olsoniana de la acción colectiva es la lógica de las asociaciones económicas (LAC 2 en el diagrama $\mathrm{n}^{\circ} 1$ ).

Las asociaciones económicas presentan, a su vez, dos variantes estructurales. Una, las "asociaciones de intereses", se refieren a colectivos de individuos que orientan la acción para el avance de intereses en el sentido fuerte (los estándares de vida y oportunidades vitales de sectores muy amplios de la población, que derivan de la estructura social estratificada); la otra, las "coaliciones distributivas", como su precisa denominación indica, designan a colectivos de individuos que explotan para su provecho una situación de monopolio sobre un área de actividad social (trátese de los pilotos del SEPLA, los maquinistas

1" Es esta lógica distintiva de la "acción colectiva informal" la que hace en buena parte inaplicable la lógica olsoniana. El punto crítico fue ya bien captado por A. Hirschman a principios de los ochenta (1982: 85-86), citando a Pascal: "La acción orientada hacia lo público pertenece ... al grupo de actividades humanas que incluye la búsqueda de comunidad, belleza, conocimiento y salvación. Todas estas actividades 'conllevan su propia gratificación', como sugiere la trillada frase, pero lo que realmente sucede en esta zona todavía necesita ser mejor comprendido. (...) [L]a característica peculiar de estas actividades ... [es] la fusión -o confusión- entre el esfuerzo de búsqueda y el logro obtenido ... Una vez se comprende esta característica esencial de la participación en la acción colectiva en pos de la mejora pública, las serias limitaciones del punto de vista 'económico' acerca de esa participación, y acerca de los obstáculos para alcanzarla, se hacen inmediatamente patentes. La lección que cabe derivar de la confusión entre el esfuerzo de búsqueda y el logro es que la distinción neta entre los costes y los beneficios de la acción orientada al interés público se desvanece, puesto que el esfuerzo de búsqueda, que debería contabilizarse en el apartado de los costes, resulta ser parte del beneficio. (...) Lejos de desentenderse y tratar de conseguir un viaje gratis, un individuo verdaderamente maximizador intentará ser tan activista como las circunstancias lo permitan, dentro de los límites demarcados por sus otras actividades y objetivos esenciales". Esta es una conclusión con la que converge, al menos en parte, el análisis de M. Revilla (1994: 188), pero en términos olsonianos (de manera que la identidad colectiva, que algo tiene que ver con el "esfuerzo de búsqueda" de Hirschman, se podría tratar como un incentivo selectivo).

${ }^{21} \mathrm{Y}$ lo hacen legitimamente, siendo ésta una de las caracteristicas distintivas de las poliarquías (véase Dahl, 1986: especialmente los capítulos 9 y 10). 
de la RENFE, los controladores aéreos, los trabajadores chilenos del cobre, o las coaliciones que se forman en ciertos estratos de la universidad pública española) ${ }^{21}$. Por lo que se refiere a las "asociaciones de intereses", la sociología sabe también mucho sobre su lógica de acción colectiva, porque una parte de ésta (LAC 3 en el diagrama ${ }^{\circ} 1$, deudora sobre todo de los estudios de C. Offe, 1992, y $\mathrm{Ph}$. Schmitter y W. Streeck, 1981) es común tanto al colectivo que forman los empresarios, como al de los trabajadores asalariados; otra parte importante, sin embargo, de la lógica de acción de esos dos grupos es bien divergente, como han mostrado Ph. Schmitter y W. Streeck (1981) entre otros (la LAC 4 del diagrama) para el caso de los empresarios ${ }^{22}$ y P. Lange et al. (1982) para el caso de los trabajadores ${ }^{23}$.

${ }^{21}$ Los "intereses" que persiguen las coaliciones distributivas son más ventajas comparativas relativas y derechos de acceso para los miembros del grupo - con independencia de los efectos sociales que producen y de los que no se corresponsabilizan (véase Pérez Yruela y Giner, 1988:26; y Olson, 1982)-, que "intereses" en el sentido anterior. La búsqueda de "ventajas", más que la defensa de intereses, desvincula de hecho, en términos prácticos, este tipo de acción colectiva del proceso de trabajo de una sociedad. La comprensión cabal de la LAC 6 del diagrama $n^{\circ} 1$, esto es, la lógica de la acción colectiva distintiva de estas coaliciones, es también deudora sobre todo de la obra de M. Olson. Se pueden distinguir tres formatos institucionales principales: las asociaciones profesionales (como los colegios profesionales); las asociaciones gremiales (como ASETMA); y los cárteles (asociaciones que regulan la provisión de un bien y, por tanto, su "precio", en régimen de monopolio u oligopolio).

22 Para éstos, la asociación formal es una de las variantes posibles de la acción colectiva (que da lugar a las organizaciones patronales: unas, "de choque", las que tratan del conflicto industrial y la negociación colectiva, como la CEOE en España; otras, "de definición estratégica", como el Cercle d'Economia de Barcelona o el Círculo de Empresarios de Madrid; y finalmente, los institutos de estudios allegados a los dos sectores anteriores, como el Instituto de Estudios Económicos español); las otras variantes son las Cámaras de Comercio y, como estudió clásicamente Wright Mills y ha recordado recientemente $\mathrm{C}$. Offe, la propia empresa y la asociación informal en clubs e instituciones sociales muy diversas donde los empresarios crean opinión y cultura de grupo.

${ }^{23}$ La asociación formal de los trabajadores da lugar históricamente a tres variantes principales: el sindicalismo de clase (es decir, las confederaciones nacionales de sindicatos que mantienen como base social potencial al conjunto de la fuerza de trabajo de una economía nacional, como es el caso de CCOO, UGT, USO, CGT etc. en España); el sindicalismo corporativo, o "amarillo" (que representa la tendencia opuesta a formar colectivos cerrados, incluso de empresa, para la negociación de las condiciones laborales y, en esta medida, se solapa con las coaliciones distributivas contiguas); y el asambleísmo (mecanismo fundamentalmente informal y democrático de toma de decisiones y canalización de acción colectiva que recoge la tradición clásica del movimiento obrero y es expresión de la "pauta dialógica" de la acción señalada por Offe y Wiesenthal, en Offe, 1992: cap. 2). Por lo que se refiere a la primera de las tres variantes (LAC 5), a mi juicio, el estudio clave es el de P. Lange et al. (1982). Aunque con menos claridad que en los casos anteriores, por tratarse de modelos de acción colectiva generales, Hirschman (1977, 1985) y Hirsch (1976) son imprescindibles para tratar el caso genérico de la lógica de la acción colectiva formal. 
La conclusión de este análisis sintético es la siguiente. En primer lugar, que la lógica de la acción colectiva de los movimientos sociales es una más entre un abanico de lógicas de acción que exhiben los entes institucionales especializados en esa labor (las "instituciones de acción colectiva") ${ }^{24}$. En segundo lugar, que, dentro de la familia a la que pertenecen los movimientos sociales (la "acción colectiva informal"), también hay lógicas plurales de la acción (siguiente apartado). Y en tercer lugar, que es injustificado hablar hoy de una única y universal lógica de la acción colectiva.

\section{LA LÓGICA DE ACCIÓN DE LOS MOVIMIENTOS SOCIALES}

Para cada diferenciación de los movimientos sociales en tipos que la sociología sea capaz, fundadamente, de establecer, podría postularse una lógica de la acción colectiva. Aunque en sentido estricto esto es cierto, también lo es que sólo tiene sentido establecer lógicas plurales de la acción si ello contribuye a una mayor precisión de la actividad investigadora porque demarca diferencias muy marcadas (estructurales) entre la acción de unos y otros tipos de movimientos sociales; esto es lo que permite la investigación rigurosa y la formulación de preguntas pertinentes. Por tanto, muchas de las clasificaciones de los movimientos sociales -por ejemplo, la de Ch. Tilly (1978; véase 1995:28), que distingue entre "reactivos" y "proactivos"-, muy útiles en ciertos aspectos de la investigación de la acción de los movimientos, lo son poco si lo que pretendemos, como es el caso aquí, es establecer el sentido global o de conjunto que cabe esperar de un determinado caso empírico de "acción colectiva informal" $\mathrm{y}$, en consecuencia, establecen las preguntas relevantes que plantear. A mi entender, son tres las variables que responden a esta exigencia: la orientación constitutiva de la acción (la distinción de $\mathrm{H}$. Blumer entre movimientos generales

\footnotetext{
${ }^{24}$ Tácitamente, muchas investigaciones parecen presuponer que, efectivamente, existe una "lógica del conflicto social" en la que se inscriben esas instituciones (véase Dahrendorf [1990], por ejemplo) que atraviesa toda o casi toda la panoplia de fenómenos identificados por Ch. Tilly más arriba. En concreto, parecen proponer que esa lógica, en síntesis, se puede identificar asi: a) un grupo de individuos mantiene intereses en común; b) y, por ello mismo, comparten una actitud de descontento relativo sobre su situación actual (en la medida que aspiran a obtener determinados bienes colectivos ahora no disponibles); c) a y b permiten predecir que los miembros del grupo tenderán a identificar un blanco (otro u otros actores sociales) y dirigir a él su protesta colectiva (generando así una situación de conflicto político) cuando se traspase un determinado umbral (en buena parte definido por el tipo de reivindicación latente del grupo); d) de tal manera que cuanto mayor es el número de individuos involucrados, más importante es socialmente el conflicto y más probable el éxito de la reivindicación (principio del efecto multiplicador de J. Coleman, 1973: 3-6).
} 
Diagrama 2.

Movimientos sociales generales y especificos

\begin{tabular}{|c|c|c|}
\hline Variables & Movimientos generales & Movimientos especificos \\
\hline Objetivos & $\begin{array}{l}\text { Difusos (sólo señalan una dirección general) } \\
\text { (p.e.: la emancipación de los trabajadores en el } \\
\text { caso del movimiento obrero) }\end{array}$ & $\begin{array}{l}\text { Definidos } \\
\text { (focalizados en uno o unos pocos objetivos tangibles) }\end{array}$ \\
\hline Organización & $\begin{array}{l}\text { Informal y difusa (más posibilidad de generar } \\
\text { organizaciones del movimiento; p.e. los sindicatos) }\end{array}$ & Definida-> convierte al colectivo en "una microsociedad" \\
\hline Liderazgo & $\begin{array}{l}\text { Rol distintivo de los líderes: no tanto la dirección como } \\
\text { la apertura de caminos innovadores + importante papel } \\
\text { de numerosos individuos anónimos en la continuidad } \\
\text { del movimiento }\end{array}$ & $\begin{array}{l}\text { Reconocido y aceptado } \\
\text { Genera cuatro tipos: cuasi-agitadores; profetas-reformadores; } \\
\text { hombres de Estado; administradores }\end{array}$ \\
\hline $\begin{array}{l}\text { Pertenencia } \\
\text { ("membresía") }\end{array}$ & No reglada & Reglada-> conciencia del "nosotros" \\
\hline Cultura de grupo & $\begin{array}{l}\text { El material escrito juega un papel fundamental de difu- } \\
\text { sión del mensaje y contiene la expresión de la protesta y } \\
\text { un bosquejo habitualmente vago de la filosofia que } \\
\text { inspira al colectivo }\end{array}$ & $\begin{array}{l}\text { Se trata de un complejo a la vez de cultura y de ideologia, } \\
\text { formado por tradiciones, valores, filosofia y normas; } \\
\text { este complejo es el que permite visualizar una "sociedad" } \\
\text { y produce un fuerte impacto en la personalidad de los } \\
\text { miembros del colectivo }\end{array}$ \\
\hline $\begin{array}{l}\text { Medios de } \\
\text { interacción }\end{array}$ & $\begin{array}{l}\text { Lecturas, conversaciones, charlas y debates } \\
\text { (terreno de la experiencia individual) }\end{array}$ & $\begin{array}{l}\text { Interacción reglada } \\
\text { (terreno de la acción concertada de los grupos) }\end{array}$ \\
\hline
\end{tabular}


y específicos); la existencia o no de mecanismos que garanticen la continuidad de la "acción colectiva informal" (la distinción que propongo entre movimientos propiamente dichos y acciones colectivas de masas); y los tipos históricos que cabe establecer analizando las oleadas de este tipo de acción que ha conocido la historia (la clasificación de los movimientos en primitivos, clásicos, nuevos, novísimos y periféricos antisistémicos). Examinamos a continuación los tres casos.

\section{Tipos estructurales: movimientos generales y específicos}

Uno de los primeros clásicos en la literatura sobre los movimientos sociales (Blumer, 1969) sigue siendo a mi entender plenamente vigente para comprender cómo lo que hemos llamado "orientación constitutiva" de un movimiento (el que establezca para sí objetivos difusos y trascendentes o delimitados y efimeros) determina dos lógicas divergentes de la acción colectiva, que dan lugar a dos tipos de movimientos (generales y específicos). Las características estructurales que $\mathrm{H}$. Blumer asigna a estos dos tipos permiten claramente establecer dos lógicas diferenciadas de acción colectiva que el investigador ha de incorporar a su utillaje teórico (y que, de hecho, se consideran hoy conocimiento adquirido en los estudios de los movimientos). En el diagrama $n^{\circ} 2$, se resumen de forma esquemática las características de estos dos tipos de movimientos sociales.

Por razones que se desprenden con facilidad de dicho diagrama, la conceptualización de H. Blumer establece la necesaria disparidad entre las lógicas de acción de los movimientos adscritos a una u otra variante. Permite también entrever cómo se vinculan entre sí, a pesar de las diferentes lógicas que adoptan, los movimientos generales y los específicos.

\section{Variantes de la acción colectiva informal}

Aunque hay poco acuerdo sobre su significación precisa, a los hechos de Mayo de 1968 o, más recientemente, de diciembre de 1995 en Francia, se les reconoce unánimemente un valor emblemático por lo que se refiere al nacimiento de nuevos actores sociales. ¿Pero cuáles?. Porque si bien resulta probado que los acontecimientos de Mayo del 68 sirven de plataforma de lanzamiento de una nueva oleada de movimientos, los "nuevos movimientos sociales" (Offe, 1992:cap. 5), ¿quién es el actor protagonista de los acontecimientos mismos? Aquí la imprecisión y falta de acuerdo es total (por ejemplo, Touraine et al., 1996, para los hechos de 1995$)^{25}$. Algo similar podría decirse de los acontecimientos desencadenados por la huelga general española de diciembre de 1988.

Aunque los términos citados (revuelta, revuelta social, movimiento) son suficientes para entendernos y para que los ciudadanos podamos debatir y crearnos imágenes sobre los acontecimientos, son insatisfactorios desde el 
R I S

REVISTA INTERNACIONAL DE SOCIOLOGLA

N 30. Septiembre-Diciembre, 2001

análisis científico-social. Proponemos aquí que la sociología de la acción colectiva debe ocuparse de fijar con precisión (y traducir en conceptos y teorías) los perfiles profundos de esos acontecimientos. Afirmamos también que los observadores que se han preocupado por designar con propiedad estos o parecidos fenómenos aparentemente enigmáticos ${ }^{26}$ buscan en vano terminologías apropiadas y puntos de referencia: acontecimientos como los citados se encuentran sin dificultad en la etapa formativa de las sociedades industriales occidentales; asimismo, historiadores sociales y sociólogos de la historia han tendido tradicionalmente a identificar ese actor sin cara al que nos referíamos, como "turba" (mob) y "muchedumbre" o multitud (crowd). El descuido es comprensible, sin embargo. Por un lado, porque ese formato de protesta popular parecía haberse extinguido en muchos países occidentales hasta la llegada de 1968. Por otro, porque la cultura científico-social ý política contemporánea manifiesta, afortunadamente, una resistencia natural a utilizar tales términos (y volver así, tácitamente, a la vieja y elitista tradición que parte de Le Bon y su psychologie des foules, 1895).

La brillante e influyente hipótesis de E. Hobsbawm (1959) sobre la "rebelión primitiva" contribuyó probable e involuntariamente a reforzar la tradición citada entre las nuevas generaciones, tanto de estudiosos de la acción informal, como de personas de la izquierda académica (quienes, de natural, son menos proclives a aceptar como legítimas nociones con tamaña carga valorativa). Como la mayor parte de sus colegas historiadores sociales y sociólogos de los movimientos premodernos E. Hobsbawm yerra al caracterizar como "turba" o "muchedumbre" al sujeto o ente institucional que protagoniza numerosas revueltas en las ciudades preindustriales ${ }^{27}$, entre otros contextos urbanos (véase Hobsbawm, 1959: cap. 7). Este enfoque metodológico de la cuestión emparenta inmediatamente el análisis (aunque sea de manera indirecta, en el caso de E. Hobsbawm) con el modelo

\footnotetext{
${ }^{25}$ Los periodistas y científico-sociales que cubren los acontecimientos de 1995, por ejemplo, hablan indistintamente de "revuelta" (E. Izraelewicz en Le Monde, publicado en El País 8.XII.1995; o E. Morin, Rebonds, 19.XII.1995), "revuelta social", "movimiento social" ("Les medias face au mouvement social de novembre-decembre 1995", dossier de prensa de la agencia RAT; o E. Marquis en Silence, $\mathrm{n}^{\circ}$ 205, junio de 1996, p. 32). Pero, si es una revuelta, ¿quién es el actor que la protagoniza? Y si es un movimiento, ¿cómo puede "desaparecer"?

${ }^{26}$ Sobre la caracterización de los acontecimientos de 1968, véase la perceptiva síntesis de Ch. Tilly (1997:58-60). Sobre la búsqueda de una caracterización precisa para acciones de masas totalmente novedosas, véase A. Ortega ("Movimientos de masas no identificados", en El Pais, 5 de enero 1998, p. 6).

${ }^{27}$ Nos referimos a ese período que G. Rudé (1970:17) data, para los casos francés y británico, de 1700 a la década de 1840 , durante el cual una sociedad se acomoda a las transformaciones desencadenadas por una industrialización acelerada.
} 
de la psicología de las masas que surge con Le Bon e influye en la corriente sociológica posterior de la conducta colectiva (Turner y Killian, 1972); modelo según el cual, sintéticamente, todo colectivo de individuos anónimos que se forma espontáneamente y actúa sin organización ni jerarquía acaba por exhibir comportamientos irracionales y es, con frecuencia, protagonista de conductas patológicas ${ }^{28}$. Hoy sabemos que una investigación seria y rigurosa de la acción colectiva no se puede permitir, ni siquiera a través de sus conceptos (en el caso que examinamos, "turba" y "muchedumbre"), establecer estas fronteras entre la normalidad y la anormalidad. Como bien sintetiza Ch. Tilly (1991:28):

"Estas dicotomías radicales [entre orden y desorden] se apoyan en la idea de que el orden social es frágil, que la diferenciación amenaza el orden social, que el cambio es arriesgado, que el cambio ilimitado genera tensión, violencia decadencia y desintegración, y que únicamente el cambio dirigido y restringido conduce a la integración, a la satisfacción y al progreso. Expresan el deseo de los que están en el poder ... de mejorar a aquellos que les rodean por medio de la coerción y de la persuasión y con los mínimos costes. Mientras continúen promulgando estas ideas, las ciencias sociales del siglo XX seguirán siendo las transmisoras de la sabiduría popular del siglo XIX".

Nuestra propuesta es, contrariamente, que los movimientos populares en los contextos urbanos tratados, entre otros, por E. Hobsbawm y G. Rudé (1970, 1971, 1981 y 2000), constituyen un económico formato institucional para canalizar la protesta colectiva en situaciones históricas donde es prácticamente

\footnotetext{
${ }^{28} \mathrm{Al}$ adoptar esta posición, además, el sociólogo se aleja de la tradición contemporánea de la sociología de la acción colectiva, algo de lo que, por supuesto, no puede culparse a E. Hobsbawm, cuya obra citada es anterior a esa tradición. R. Turner y L. Killian (1972:2-4) exponen con claridad la posición que se ha sintetizado: "La noción de psicología de la multitud o psicología de la turba sugiere [la] explicación [de que] los miembros de la multitud son personas perfectamente normales que reaccionan ante cierto tipo de influencia inusual mientras se hallan en la situación de multitud. (...) El sociólogo acostumbrado a estudiar las regularidades de la vida grupal convertidas en predecibles gracias a las estructuras sociales estables y normas tradicionales, se hace también preguntas acerca de las fuerzas sociales y psicológicas que entran en juego en situaciones donde las convenciones usuales dejan de guiar las actividades humanas. El sociólogo se ha acostumbrado a usar el término conducta colectiva para distinguir esta clase de actividad de la conducta convencional, tradicional, normal... Un punto de vista corriente de la conducta colectiva implica que ésta consiste sencillamente en la violación de las normas habituales por parte de un gran número de personas y al mismo tiempo; implica por tanto que se trata de conducta desorganizada, desviada". Las cosas se conciben hoy de manera muy distinta en el seno de la nueva tradición de la sociología de la acción colectiva, como bien expresa Ch. Tilly (1991:71): "las rebeliones, las protestas, la violencia colectiva y otras formas de acción conectadas con las anteriores resultan de la búsqueda racional de intereses compartidos". Véanse también al respecto los comentarios de C. Calhoun (1995:200-201).
} 
RIS

inviable dar continuidad a la protesta por medio de entes organizativos más evolucionados. "Turba" es una denominación que, además de intrínsecamente peyorativa (como acabamos de indicar: subraya que se trata de una conducta constitutivamente anormal), no capta el meollo sustantivo de un fenómeno (a saber, una acción de masas que opera con elevada espontaneidad, carente de aparato organizativo estable ni dirección jerárquica, lo cual garantiza la discontinuidad de la protesta ${ }^{29}$ ) al que responde mejor la denominación que proponemos de "acción colectiva de masas". Esta es la forma de protesta popular más habitual en las grandes ciudades preindustriales y en la primera era de la industrialización europea, que E. Hobsbawm define así (1968:145; obsérvese la incomodidad del autor al seleccionar el término):

"Preferiría discutir algo que mejor describiremos como un remolino permanente en la vida urbana que como una corriente. Lo llamaremos, valiéndonos de la frase inglesa clásica, "the mob" (la turba) porque la inconstancia que chocó a quienes observaban era una de sus características superficiales más evidentes ${ }^{30}$. La turba puede definirse como el movimiento de todas las clases urbanas pobres encaminado al logro de cambios políticos o económicos mediante la acción directa -es decir, por el motín o la rebelión-, pero un movimiento que todavía no estaba inspirado por ninguna ideología específica... Era un movimiento prepolítico y, como tal, fenómeno primitivo en nuestro sentido".

Nuestra hipótesis es que, con un contenido sustancialmente cambiado, este formato institucional reaparece en la Europa contemporánea preludiando, no reivindicaciones elementales sobre los estándares de vida por parte de masas relativamente amorfas, sino reivindicaciones sofisticadas relativas a la ciudadanía y la calidad de la vida política por parte de "masas"

\footnotetext{
29 Pero también una elevada eficiencia en términos de intimidación de los otros actores en presencia. Para el caso de las acciones en contextos preindustriales, véase G. Rudé (1970:19).

"Nota de E. Hobsbawm: "Espero que quedará claro de lo que sigue que no todas las asonadas urbanas son 'asonadas de la turba', ni tampoco es una muchedumbre toda reunión importante de habitantes de la ciudad ... Como se han utilizado pocas palabras de modo tan indiscriminado como el de 'turba', esta puntualización puede no estar fuera de lugar". Una advertencia similar referida al término "muchedumbre" o "multitud" (crowd) puede encontrarse en la frase inicial del ejemplar estudio de E.P. Thompson (1971:76) sobre la "economía moral" de la multitud.

"Salvador Giner alertó ya en su día sobre el carácter peyorativo y, en el fondo, elitista del uso de la denominación "masa" para referirnos a un actor social. En este trabajo se utiliza el término en plural y con frecuencia entrecomilladamente para señalar que, a falta de mejor denominación, lo que hacemos es subrayar con ella los aspectos cuantitativos (o de tamaño) de una protesta y su fundamental carencia de organización estable; pero en absoluto con una connotación despectiva, sino más bien al contrario.
} 
autoconciencia y preparación cultural (este es el caso, según creemos, de los acontecimientos de diciembre de 1995 en Francia y del ciclo de protesta en España entre 1986 y 1997) ${ }^{32}$. Las diferencias fundamentales entre ambas formas residen tanto en el contenido de la protesta, como en la ausencia o presencia de la variable estructural "orden político poliárquico". Son, pues, diferencias decisivas. Pero la forma es la misma: la forma utilizada en contextos preindustriales y que $\mathrm{E}$. Hobsbawm no duda en calificar de protesta "prepolítica" es contemporáneamente el vehículo que utiliza, esporádica pero consistentemente, la ciudadanía occidental para reivindicar una mayor calidad de la vida política ${ }^{33}$. Lo que nos interesa destacar ahora es que este formato institucional de acción colectiva (paradójicamente, por así decir, antiinstitucional) sigue una lógica de acción divergente en muchos puntos de la de los movimientos sociales. La diferencia decisiva es que éstos mantienen una red de coordinación de la protesta sobre bases permanentes (generando eventualmente inclusive organizaciones del movimiento) y la acción colectiva de masas no (sólo desarrolla estructuras de coordinación de la propia acción y sobre el terreno $)^{34}$. Esta diferencia ya la entrevió E. Hobsbawm (1968:147, cursivas nuestras):

"La turba clásica no se soliviantaba solamente en son de protesta, sino que lo hacía porque esperaba sacar algún beneficio de sus disturbios. Suponía que las autoridades se sentirían afectadas por sus movimientos, y probablemente también que harían algún tipo de concesión inmediata; y es que la muchedumbre [ $m o b$ en el original, 1959:111] no era solamente una reunión casual de gentes unidas con algún propósito del momento, sino, de modo palmario, una entidad permanente, aun cuando permaneciese escasas veces organizada como tal. Lo estuvo algunas

\footnotetext{
32 Los "movimientos" que P. Sztompka identifica en la coyuntura de 1989 (véase más arriba) son, en realidad, una variante -en condiciones no poliárquicas- de esta acción colectiva de masas. Por esto, se "desvanecen" poco después.

"La reivindicación, para ser más precisos, consiste en demandar una vida pública con alguna "calidad" donde las palabras "democracia" y "participación" tengan algún sentido. Debo precisar que las movilizaciones por Miguel Angel Blanco (1997) no parecen encajar en esa perspectiva; pero la cuestión no es clara y, en cualquier caso, comparten con las otras acciones colectivas de masas mencionadas que un conjunto numeroso de individuos buscan en la calle un protagonismo político que los canales institucionales no permiten.

it Este es el papel que, al menos en parte, jugaron a nuestro entender las organizaciones sindicales convocantes de la protesta tanto en el caso francés de 1995 como en el español de 1988, desbordadas ampliamente (como "organizadores" y por lo que respecta a las reivindicaciones oficiales) en ambos casos por la asistencia y actitudes de una "masa" que se erigió, rápidamente, en el sujeto de la protesta. La diferencia crucial entre movimiento y lo que aquí denominamos acción colectiva de masas fue ya captada tempranamente por R. Turner y L. Killian (1972:111) al referirse a la "muchedumbre difusa": "El movimiento social exhibe una continuidad y estabilidad de estructura y normas que no se encuentra en la muchedumbre compacta de carácter efimero".
} 
veces, por más que las formas de organización permanente de la plebe -fuera de los gremios artesanos- están por investigar; lo estuvo por ejemplo con las hermandades religiosas de las ciudades europeas, o en los varios pangs chinos. [La cursiva es nuestra]

La percepción es exacta. Lo que aquí proponemos, sin embargo, es que la teoría social sustituya los términos valorativos como "turba", "multitud" y "muchedumbre" por el más técnico de "acción colectiva de masas" y que, a la vez, aplique a su estudio, al igual que hace con las "asociaciones económicas" y otros formatos institucionales de la acción, no la imprecisa y deficiente perspectiva psicologista de estudio provinente de Le Bon y la corriente de la conducta colectiva, sino la sólida y empíricamente fundada sociología de la acción colectiva contemporánea.

\section{Los tipos históricos de los movimientos sociales}

La tercera y última variante de diferenciación interna de los movimientos sociales que vamos a considerar tiene que ver con las oleadas que aparecen a lo largo de la historia. No hay tampoco aquí una lógica unitaria de la acción colectiva, una lógica que convierta en indistinguibles, o fácilmente asimilables entre sí, las acciones, por ejemplo, de S. Giuliano (y la base social que le apoya en la Sicilia de los años cincuenta) y, pongamos por caso, las del movimiento okupa actual y el ludismo de los inicios de la industrialización europea. La razón es fácilmente comprensible: cada forma de organización social $-\mathrm{y}$ sus variantes socioestructurales internas- genera un modelo característico de conflicto y, derivadamente, ciertas formas de movimientos sociales posibles en las condiciones presentes. Partiendo de esta premisa, el objetivo de investigación de la sociología de los movimientos tiene que ser, en este punto, establecer unos tipos históricos que recojan adecuadamente las diferencias estructurales que se observan en los movimientos debido a su pertenencia a un tipo u otro de modelo del conflicto social. Mi propuesta tentativa está contenida en el Diagrama $\mathrm{n}^{\circ} 3$, que es objeto de comentario a continuación ${ }^{35}$.

\footnotetext{
${ }^{35} \mathrm{La}$ ocurrencia sobre los cinco tipos que se distinguen en el diagrama $\mathrm{n}^{\circ} 3$ es compartida con el profesor T. Herreros, con quien establecí el programa de la asignatura "Movimientos sociales" (optativa de la Licenciatura de Sociología de la UB) en el curso 1999-2000 y que contiene esa distinción. El contenido de los tipos y los argumentos son míos. La clasificación tiene un objetivo básicamente pedagógico (para su uso en las tareas docentes) y soy consciente de que en diversos puntos, o bien se fuerza más de lo debido la homogeneidad de los fenómenos considerados para (sigue en página 52 )...
} 


\section{RIS}

PEVISTA INTERNACIONAL DE SOCIOLOGI

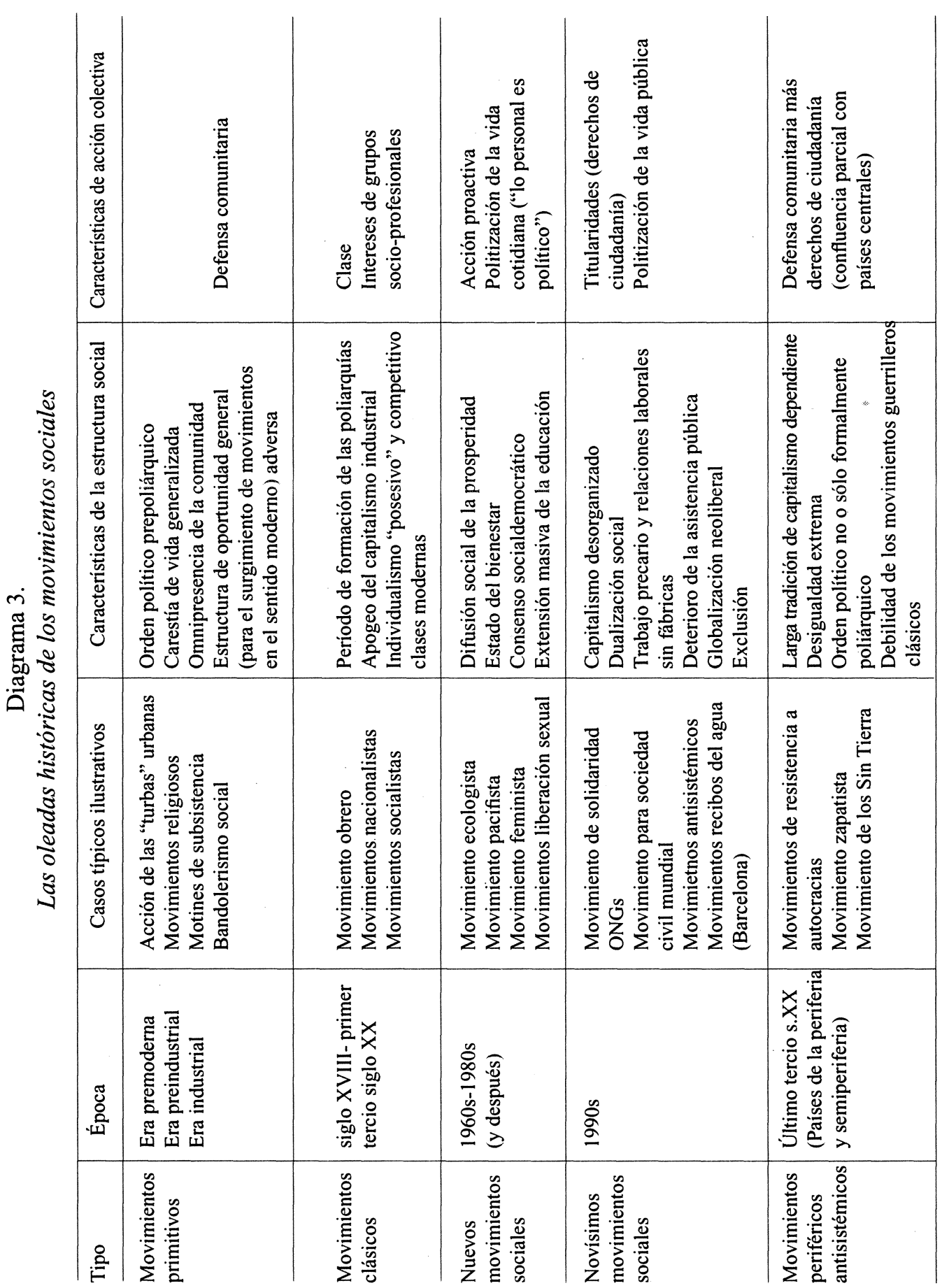

51 
RIS

RETISTA INTERNACIONAL DE SOCIOLOCi.

$N^{*}$ 30. Septiembre-Diciembre. 2001

SALTADOR AGLILAR

Al establecer una clasificación en tipos históricos, ocurre con los movimientos sociales algo similar a lo que ocurre con las formas de organización social a lo largo de la historia humana (Aguilar, 2001: cap.1): se establecen por alguna convención teórica o con alguna finalidad analítica prioritaria (lo que significa que la clasificación nunca puede considerarse única ni definitiva); pero, en cualquier caso, es la modernidad la que demarca la gran línea divisoria previa a cualquier taxonomía. El observador puede proceder a una división meticulosa y pormenorizada en tipos diversos (operación que, hasta cierto punto, como decimos, es una convención, a la vez que depende de las preguntas que se haya formulado ese observador y el punto de vista central con que opera), pero finalmente hay una distinción previa y mayor, de trazo grueso: los movimientos premodernos (las sociedades premodernas) y los movimientos modernos (las sociedades modernas), que conforman realidades drástîcamente diferenciadas.

En el caso de los movimientos sociales, la línea divisoria fundamental aludida, que genera dos tipos de acción colectiva estructuralmente diferentes, es también clara. Enfrenta en lo fundamental dos tipos de situación (Tilly, 1969, 1995 y 1998: 35-36; Tarrow, 1997; Franzosi, 1995: cap. 4). De un lado, formas de interacción reivindicativa fundamentalmente locales, cerradas ("provincianas") y particularistas, que se dirigen no contra entidades abstractas que simbolizan la autoridad, sino contra personajes próximos que la encarnan en el contexto local (el comerciante, el clérigo, etc.). De otro lado, formas de interacción reivindicativa fundamentalmente de ámbito nacional, con expresiones progresivamente generales y que se dirigen a grandes actores asociativos y al Estado. Con ello se ha operado un cambio crucial de repertorio, ya que los movimientos en el sentido moderno nacen en esa coyuntura:

"La palabra repertorio sirve para identificar un conjunto limitado de rutinas que son aprendidas, compartidas y practicadas por medio de un proceso de elección relativamente deliberado. Los repertorios son creaciones culturales aprendidas, pero no descienden de ninguna filosofia abstracta ni toman cuerpo como resultado de la propaganda política: emergen de la lucha. La gente aprende a romper ventanas como forma de protesta, a atacar a prisioneros engrilletados, derrocar edificios deshonrados, organizar manifestaciones públicas, efectuar peticiones,

\footnotetext{
un tipo, o bien carecemos de investigación solvente que permita sostener con total fundamento algunas de las proposiciones. La misma denominación de los tipos (especialmente en el caso de los "primitivos", "nuevos" y "novísimos" movimientos) ya indica las dificultades para establecer categorias bien fundadas. Por otro lado, como ha señalado persuasivamente C. Calhoun (1995), ni siquiera el predominio de los movimientos "clásicos" en su momento está exento de severas anomalías y excepciones, por no hablar de que se pueden identificar también "nuevos" movimientos como mínimo en la primera parte del siglo XIX
} 
programar reuniones formales, organizar asociaciones de intereses especiales. En cualquier momento particular de la historia, sin embargo, aprenden únicamente un abanico relativamente limitado de formas de actuar colectivamente" (Tilly, 1995:26).

En parte, esta era también la intención de E. Hobsbawm en su estudio clásico (1959) sobre la rebelión primitiva: demarcar con claridad la gran diferencia entre los movimientos sociales previos y posteriores a la "gran transformación" del siglo XVIII europeo (Tilly, 1969:21). Sin embargo, a la vista del trayecto posterior seguido por el mundo occidental moderno, y en particular de la coyuntura de 1989, parece hoy insostenible la hipótesis central de E. Hobsbawm según la cual la capacidad de creación de redes organizativas (partidos y sindicatos obreros, mayormente) en contextos nacionales constituye un indicador inequívoco de la modernidad de la protesta popular (de adaptación a las exigencias del mundo moderno $)^{36}$. Hoy parece poco discutible que los movimientos sociales y políticos populares de la era clásica sufren un declive político profundo y probablemente irreversible ${ }^{37}$ y que los ideales sustantivos de emancipación que atribuimos a la modernidad han tomado cuerpo en otros entes institucionales. Los "rebeldes evolucionados" del mundo de hoy, aunque diferentes de ambos, tienen probablemente más en común con esos "rebeldes primitivos" supuestamente inadaptados de E. Hobsbawm, que con los, llamémosles así, "rebeldes institucionales" (sindicatos y partidos obreros de masas) que el gran historiador británico postulaba en 1959 como indicadores de la protesta moderna. La conclusión debe ser, según creemos, que la sociología de los movimientos sociales debe prestar atención creciente a esta diferenciación en tipos históricos y prescindir, en la medida que la investigación lo permita, de las dicotomías de trazo grueso con las que se han manejado tradicionalmente en

\footnotetext{
"La hipótesis original de E. Hobsbawm fue ya objeto en su dia de una aguda crítica por parte de J. Martínez Alier (en Cuadernos de Ruedo Ibérico) por incluir al anarquismo entre las "rebeliones primitivas", es decir, entre las que no han sabido adaptarse a la modernidad capitalista. El tiempo transcurrido permite concluir, según creemos, que es indiscutible el acierto de la crítica de J. Martínez Alier y probado el resurgir del anarquismo en forma de cultura política de los "nuevos movimientos sociales" que surgen en las oleadas de los años sesenta y de los noventa.

${ }^{i 7}$ Descrito por el propio E. Hobsbawm (1989).

" Secundariamente, que las racionalizaciones políticas, incluso las que se elaboran con las mejores intenciones, no son buenas guias para la investigación científico-social. Por otro lado, hace ya tiempo que las divisorias de trazo grueso han sido erradicadas de la teoría social. Para el caso, que mantiene paralelismos con el que aquí tratamos, de las dicotomías de los clásicos de la sociología para caracterizar la "gran transformación" (comunidad y asociación; status y contrato, etc.), véase J.A. Bill y R.L. Hardgrave (1992).
} 
este punto las ciencias sociales ${ }^{38}$. El Diagrama $\mathrm{n}^{\circ} 3$ sugiere que, como mínimo, se pueden distinguir cinco lógicas históricas ${ }^{39}$ diferentes de la acción colectiva en el seno del mismo fenómeno (el movimiento social) -a las que corresponde una orientación central peculiar en cada caso- lo suficientemente contrastadas entre sí, además, como para exigir su tratamiento por separado.

1.- Defensa del grupo. Para volver al ejemplo anterior, puede decirse que el bandolerismo social que practica Giuliano obedece a una lógica compleja, pero que gira, en lo fundamental, sobre la necesidad de la defensa comunitaria ante la intrusión de factores externos, "extraños" y mal comprendidos por los miembros del grupo. En un contexto de conflicto social (pre-moderno) como éste y el de los otros casos citados en el cuadro, puede señalarse, como resume bien $\mathrm{R}$. Franzosi (1995:103) citando a C. Calhoun, que "[u]n sentido de comunidad y la solidaridad de los vínculos tradicionales proporcionan las bases para la acción colectiva en la economía moral".

2.- Intereses de clase. Los movimientos "clasicos" surgen en la etapa formativa de la sociedad industrial moderna y giran alrededor de la noción de clase y, más concretamente (Offe, 1992), de los intereses de grupos socioprofesionales (trabajadores asalariados y empresarios, principalmente). Por un lado, la lógica de la acción colectiva de estos movimientos se aleja de la perspectiva de la "economía moral" (y la noción concomitante de comunidad) para entrar en esa noción de intercambio político que caracteriza a la era moderna y que A. Pizzorno ha resumido con maestría como la búsqueda de fines negociables. Por otro lado, sin embargo, una parte de los movimientos clásicos (movimientos nacionalistas y parte del movimiento obrero) comparten la nueva perspectiva con un anclaje en nociones preemodernas de comunidad. En una mayoría de casos se cumple, de todas maneras, el diagnóstico de D. Bell (1976:194-197) de que "durante más de cien años, la 'cuestión obrera' dominó a la sociedad occidental. El conflicto entre trabajadores y patronos (bien fuera el capitalista o el gerente de la corporación) oscurecía todos los demás conflictos y era el eje alrededor del cual giraban las divisiones sociales fundamentales. (...) Las sociedades industriales son sociedades regidas por la economía, es decir, se organizan en torno a un principio de eficiencia funcional cuyo desiderátum es obtener 'más

\footnotetext{
${ }^{39}$ Los estudios utilizados para establecer los rasgos de cada caso son los siguientes. Para los movimientos "primitivos": Hobsbawm (1959, 1969 y 1973), Rudé (1970, 1971, 1981 y 2000), Thompson (1971), Cohn (1981) y Thrupp (1970). Para los movimientos "clásicos": Hobsbawm (1964, 1968 y 1984), Offe (1992:cap. 5), Dolleans (1969), Droz (1968), Calhoun (1995) y Jacoby (1995). Para los "nuevos" movimientos sociales: Offe (1992:cap. 5), Calhoun (1995) y Dalton y Kuechler (1992). Para todos los casos, McAdam y otros (1999), Franzosi (1995) y Zald y McCarthy (1987).
} 
por menos' y elegir la forma de acción más 'racional"'.

3.- Politización de la vida privada. La aparición de los "nuevos" movimientos sociales señala un cambio de registro del conflicto social. Emergen en el seno de una nueva era, la del "capitalismo del bienestar" y las sociedades postindustriales, y son, a nuestro entender, la primera expresión de la herencia de 1968. La noción premoderna de comunidad no sólo no desaparece, sino que cobra en ellos un sentido diferente y totalmente contemporáneo ( $\mathrm{y}$, por tanto, en cierta forma antitético del anterior): el sentido de pertenencia a un grupo sirve aquí no para asfixiar, sino para realzar la individualidad. La clave de la lógica de acción de estos movimientos es la politización de la vida privada, la extensión y el ennoblecimiento de la acción política, y es así como empieza a tomar cuerpo el legado del 1968: lo que cuenta para el cambio social humanizador es, ante todo, la transformación drástica de los entornos personales donde se mueven los individuos en su vida cotidiana; y después, sólo en segundo término, el poder político y el Estado, y no al revés ${ }^{40}$. Inevitablemente, una concepción como ésta presiona para que los "nuevos" movimientos se puedan identificar más como grupos de afinidad que como instituciones de acción colectiva creadas para satisfacer instrumentalmente un amplio abanico de necesidades de su base social (lo cual, al menos sobre el papel, era la pretensión de los movimientos "clásicos" vinculados a la clase).

4.- Politización de la vida pública. El segundo legado de 1968 consiste en proyectar sobre la política organizada o política de intereses de las poliarquías el nuevo sentido que de la actividad política (entendida como servicio cívico en pos del bien público) establecen los "nuevos" movimientos. Estos empiezan, por decirlo así, por la vida y las relaciones sociales en la esfera privada, pero a la altura de la década de 1990 empieza a proliferar en Europa un conjunto de

\footnotetext{
${ }^{40}$ Este fue uno de los impactos importantes de la cultura del 68, cambiar el sentido de la política de la izquierda. Como dicen G. Arrighi, T. Hopkins e I. Wallerstein (1999:86): "No podemos comprender 1968 a no ser que lo contemplemos simultáneamente como un cri de coeur contra las maldades del sistema mundial y como un cuestionamiento fundamental de la estrategia de la oposición de la vieja izquierda ["los comunistas de la Tercera Internacional, los socialdemócratas de la Segunda y los movimientos nacionalistas (especialmente fuera de Europa)", p. 85] frente al sistema mundial". C. Calhoun (1995:191 y ss.) denomina "autoejemplificación" un aspecto particular muy importante dentro de la tendencia de los NMS a la transformación del entorno inmediato: la insistencia en que los colectivos políticos deben ante todo reflejar en su propio comportamiento y organización interna las virtudes de sus objetivos y reivindicaciones proclamados, algo que les aleja con determinación de la cultura política de la vieja izquierda. La idea aparece con facilidad en la cultura política de los nuevos movimientos y, en general, de la era contemporánea; a título de ejemplo, citemos la hermosa primera estrofa de "Mucho, poquito y nada", del gran Daniel Viglietti, cantautor uruguayo: "Si yo no cambio un poco / mis fallas, mis males / cómo cambiar entonces / las tierras, los mares".
} 
movimientos que desplazan hacia la esfera pública ese radicalismo político, en realidad heredero también de la Revolución francesa. Pienso que en los años noventa han surgido indicios serios en varios países de la OCDE de que una nueva oleada de movimientos está a la vista; éstos, "novísimos", se emparentan con los "nuevos" movimientos, pero presentan una característica central, novedosa, de lucha por las titularidades (es decir, según aclaran A. Sen y R. Dahrendorf, de derechos de acceso a oportunidades vitales propias de la ciudadanía).

5. Ciudadanía y comunitarismo en condiciones no poliárquicas. Los movimientos antisistémicos en la periferia, finalmente, constituyen un interesante caso de movimientos a la vez reactivos (defensa comunitaria en condiciones de vida generalizadas de gran privación) y proactivos (exigencia de derechos de acceso a una calidad de vida política propia de democracias avanzadas) con una lógica distintiva propia.

Este sintético repaso de una forma de entender los tipos históricos de los movimientos sociales muestra un tercer fundamento para comprender las lógicas plurales de la acción colectiva que subyacen a ellos y que orientan las acciones de sus miembros. No hay más remedio que abandonar las nociones heredadas sobre la lógica de la acción colectiva.

\section{CONCLUSIONES}

El contenido del análisis abordado en este artículo puede sintetizarse en cuatro conjuntos de ideas que se exponen a modo de conclusión en estas páginas finales.

La primera idea es que, como suele ser frecuente en la investigación científico-social, el investigador parte de unos elementos intuitivos de base empírica suscitados por un haz de acontecimientos o fenómenos que llaman su atención y le predisponen a llevar a cabo investigaciones específicas. En este caso, se trata de tres densos episodios de acción colectiva que mantienen ciertas características en común. En primer lugar, las grandes movilizaciones de masas que contribuyen a desencadenar los cambios de la coyuntura histórica de 1989 (de las que se proponen como emblemáticas las de Leipzig de octubre y las de Berlín Este de noviembre de ese año). En segundo lugar, el ciclo de movilizaciones españolas que se produce entre 1985 y 1997 (varias huelgas generales, las manifestaciones de 1986 sobre el referéndum de la OTAN y de 1990-1991 contra la Guerra del Golfo, así como las movilizaciones suscitadas por el asesinato de Miguel Angel Blanco en julio de 1997). Y en tercer lugar, la agitación social francesa de finales de 1995. El elemento común a todos estos fenómenos es la intensidad de la protesta, la ausencia de un actor formal que los protagonice (a pesar de que una batería de actores formales constituyen la 
base de coordinación de una protesta popular que, sin embargo, les desborda con amplitud) y la eficiencia política de la movilización. Pero el intento de interpretarlos suscita ciertos problemas e incluso enigmas: el actor sin rostro que protagoniza la acción, ¿es un movimiento social, o de qué se trata? Y si es un movimiento social, ¿cómo es que "desaparece" a continuación? ¿Cómo interpretar esos ciclos de protesta?

La segunda idea es la de que, confrontado con problemas de interpretación y enigmas varios, el investigador recurre por lo general a la teoría disponible. En el caso que nos ocupa, nuestro artículo propone que esa teoría está formada por tres ítems de gran calado. Desde la sociología política y para interpretar fundamentalmente los episodios de protesta, se propone que hay un consenso ortodoxo que gira alrededor de la teoría de los grupos de interés (procedente de la tradición de Bentley y Truman) y de la lógica de la acción colectiva de $\mathrm{M}$. Olson y sus continuadores. El artículo intenta mostrar la aparatosa ineficiencia de ambas tradiciones teóricas para explicar fenómenos como los reseñados, y los motivos principales que permiten entender esa inadecuación. Desde la sociología del cambio social, ejemplificada por el trabajo de P. Sztompka, se propone que la teoría heredada vincula causalmente el conflicto social con el cambio y atribuye a la acción colectiva (y centralmente, dentro de ésta, a los movimientos sociales) el papel de desencadenante universal de las transformaciones sociales; se identifican en concreto, además, las movilizaciones de 1989 mencionadas, con la acción de movimientos sociales. El artículo muestra la inadecuación de esta noción (la acción colectiva no es, ni mucho menos, la única expresión empírica del conflicto social en una comunidad, ni los movimientos la única expresión de la acción colectiva) y la inexistencia de una lógica unitaria de la acción de los movimientos; se propone además que los actores colectivos de 1989 no son movimientos sociales, aunque se ubican dentro de la acción colectiva informal. Las tres ramas teóricas seleccionadas (la teoría de los grupos de interés, la lógica olsoniana y la sociología del cambio de la corriente principal) parecen compartir un fundamento erróneo central en la noción de una lógica unitaria de la acción colectiva para todos los fenómenos de protesta y movilización, y son, en conjunto, de escasa utilidad para comprender acontecimientos como los reseñados.

La tercera idea es la de que la inutilidad de la teoría hegemónica obliga al investigador a reformular los componentes relevantes del corpus teórico disponible para adecuarlos a sus preguntas. La propuesta del artículo en este punto es doble. Por un lado, se propone que durante las últimas tres décadas la sociología de la acción colectiva ha hecho novedosas y decisivas aportaciones que permiten entrever una teoría alternativa al consenso teórico ortodoxo; y que esas aportaciones permiten distinguir con claridad, como mínimo, no una, sino seis lógicas principales de la acción colectiva, una argumentación que, sin duda, permite afirmar el carácter plural y no unitario de esa lógica. En particular, 
RIS

REVISTA INTERNACIONAL DE SOCIOLOGÍA

№ 30, Septiembre-Diciembre. 2001

SALVADOR AGUILAR

el artículo muestra que para el caso de la acción colectiva informal (donde se ubican los movimientos) hay tres grandes motivos que permiten afirmar la existencia de lógicas plurales de la acción: los movimientos deben diferenciarse conceptualmente del actor "sin rostro" que opera carente de organización estable y definida (que los historiadores sociales han denominado tradicionalmente "turba" o "multitud"); los movimientos se diferencian interna y constitutivamente en generales y específicos (exhibiendo ambas variantes formas no coincidentes de acción); y deben diferenciarse también según su adscripción a uno u otro de los tipos históricos conocidos. El trabajo, por otro lado, no ofrece una teoría propia de la acción colectiva alternativa al "consenso ortodoxo", sino una taxonomía y un esquema conceptual (Homans, 1964) que fundamenten la formulación "regional" de teorías de la acción colectiva y una comprensión adecuada de las teorías ahora disponibles (circunscritas a ciertos aspectos de la acción política posible de los individuos). La conclusión es que la lógica de la acción colectiva es claramente múltiple, no unitaria.

La cuarta y última idea contenida en el artículo consiste en plantear la hipótesis de que, en las últimas décadas, se está produciendo lo que bien pudiera ser una renovación del repertorio de la protesta occidental. Esta, en su etapa postindustrial, vuelve a contemplar, con alguna reiteración, el recurso de ciertas protestas a las movilizaciones de masas carentes de organización estable, aunque esta vez el perfil de este actor "sin rostro" sea muy diferente, y más sofisticado, que sus precedentes históricos tradicionales. El trabajo, sin embargo, propone que hay motivos fundados para denominar a este formato de movilización "acción colectiva de masas", en lugar de los tradicionales "turba", "multitud" o "muchedumbre", y para aplicar a su estudio los instrumentos teórico-empíricos de la sociología contemporánea de la acción colectiva.

\section{BIBLIOGRAFÍA}

AGUILAR, S. (1994), Estructura social i acció col.lectiva: la lògica de l'acció sindical, Tesis doctoral, Universidad de Barcelona.

(2001), Ordre i desordre. Manual d'estructura i canvi de les societats, vol. 1, Dades, interpretacions, teories, Editorial Hacer, Barcelona.

ARRIGHI, G., T. HOPKINS e I. WALLERSTEIN (1999), Movimientos antisistémicos, Akal, Madrid.

BELL, D. (1967), The end of ideology: on the exhaustion of political ideas in the fifties, Free Press, Nueva York.

(1976), El advenimiento de la sociedad postindustrial, Alianza Ed., Madrid. 
BILL, J.A. y R.L. HARDGRAVE (1992), "Modernización y desarrollo político", en T. Carnero (coord.), Modernización, desarrollo político y cambio social, Alianza Ed., Madrid.

BLUMER, H. (1969), "Social movements", en B. McLaughlin (ed.), Studies in social movements: a sociopsychological perspective, pp. 8-28. Free Press, Nueva York.

CALHOUN, C. (1995), "'New social movements' of the early nineteenth century", en M. Traugott (ed.), Repertoires and cycles of collective action, Duke University Press, Durham.

COHN, N. (1981), En pos del milenio: revolucionarios milenaristas y anaquistas misticos de la Edad Media, Alianza Ed., Madrid.

COLEMAN, J. (1973), “Loss of power”, American Sociological Review, n 38, pp. 1-17.

DAHL, R. (1986), Democracy, liberty, and equality, Norwegian University Press, Oslo.

DALTON, R. y M. KUECHLER (comps.) (1992), Los nuevos movimientos sociales, Ed. Alfons El Magnànim, Valencia.

DAHRENDORF, R. (1990), El conflicto social moderno, Mondadori, Madrid.

DOLLEANS, E. (1969), Historia del movimiento obrero, 3 vols., Ed. Zero, Madrid.

DROZ, J. (1968), Historia del socialismo, Edima, Barcelona.

FRANZOSI, R. (1995), The puzzle of strikes. Class and State strategies in postwar Italy, Cambridge University Press, Cambridge.

GOUREVITCH, P. et al (1984), Unions and economic crisis: Britain, West Germany, and Sweden, Allen and Unwin, Londres.

GURR, T.R. (1969), "A comparative study of civil strife", cap. 17 de H.D. Graham y T.R. Gurr (eds.), The history of violence in America, Bantam Books, Nueva York.

HIRSCH, F. (1976), Social limits to growth, Harvard University Press, Cambridge.

HIRSCHMAN, A. (1977), Salida, voz y lealtad. Respuestas al deterioro de empresas, organizaciones y estados, Fondo de Cultura Económica, México.

(1982), Shifting involvements: private interest and public action, Blackwell, Oxford.

HOBSBAWM, E.J. (1959), Primitive rebels: studies in archaic forms of social movements in the 19th and 20th centuries, Norton, Nueva York (Las citas corresponden a la reimpresión norteamericana de Norton o la versión castellana de 1968, Rebeldes primitivos, Ariel, Barcelona).

(1964), Labouring men: studies in the history of labour, Basic Books, Nueva York.

(1969), Bandits, Dell, Nueva York. 
RIS

RETISTA INTERNACIONAL DE SOCIOLOCÍA

N॰ 30. Septiembre-Diciembre. 2001

SALVADOR AGUILAR

(1973), Revolutionaries, Meridian, Nueva York.

(1984), Worlds of Labour: further studies in the history of Labour, Weidenfeld \& Nicolson, Londres.

(1989), "Farewell to the classic Labour Movement?", New Left Review; vol. 173, pp. 69-74.

HOBSBAWM, E. y G. RUDE (1968), Captain Swing: a social history of the great English agricultural uprising of 1830, Pantheon, Nueva York.

HOMANS, G. C. (1964), “Contemporary theory in sociology”, en R.E.L. Faris (ed.), Handbook of modern sociology, Rand McNally, Chicago.

JACOBY, S. (1995), The workers of nations: industrial relations in a global economy, Oxford University Press, Nueva York.

KNOKE, D. (1990), Organizing for collective action: the political economies of associations, Aldine de Gruyter, Hawthorne.

LANGE, P. (1977), "La teoria degli incentivi e l'analisi dei partiti politici”, Rassegna Italiana di Sociologia, 4, X-XII.

LANGE, P., G. ROSS y M. VANNICELLI, (1982) Unions, change and crisis, Allen \& Unwin, Londres.

LE BON, G. (1969), The crowd: a study of the popular mind, Ballantine, Nueva York (edición original francesa de 1895 ).

LICHBACH, M.I. (1998), The rebel's dilemma, The University of Michigan Press, Ann Arbor.

McADAM, D. y S. TARROW y Ch. TILLY (1997), "Toward an integrated perspective on social movements and revolution", en M. I. Lichbach y A. Zuckerman (eds.), Comparative politics: rationality, culture and structure, Cambridge University Press, Cambridge.

McADAM, D., J. McCARTHY y M. ZALD (eds.) (1999), Movimientos sociales: perspectivas comparadas, Istmo, Madrid.

MARWELL, G. y P. OLIVER (1984), "Collective action theory and social movements research", en L. Kriesberg (ed.), Social movements, conflicts, and change, vol. 7, pp. 1-27, JAI Press, Greenwich.

MELUCCI, A. (1996), Challenging codes: collective action in the information age, Cambridge University Press, Cambridge.

NEVEU, E. (1996), Sociologie des mouvements sociaux, La Decouverte, París (edición castellana en Edit. Hacer, Barcelona 2002).

OFFE, C. (1992), La gestión politica, Ministerio de Trabajo, Madrid.

60 
OLSON, M. (1965), The logic of collective action: public goods and the theory of groups, Harvard University Press, Cambridge, Mass. (Las citas se hacen sobre la edición de 1982).

(1982), The rise and decline of nations: economic growth, stagflation, and social rigidities, Yale University Press, New Haven.

(1990), "The logic of collective action in Soviet-type societies", Journal of Soviet Nationalities $\mathrm{n}^{\circ} 1$, verano, pp. 8-27.

(2000), Power and prosperity: outgrowing communist and capitalist dictatorships, Basic Books, Nueva York.

PÉREZ LEDESMA, M. (1994), “'Cuando lleguen los días de la cólera' (Movimientos sociales, teoría e historia)", Zona Abierta, $\mathrm{n}^{\circ} 69$, pp. 51-120.

PÉREZ YRUELA, M. y S. GINER (dirs.) (1988), El corporatismo en España, Ariel, Barcelona.

REVILLA, M. (1994), "El concepto de movimiento social: acción, identidad y sentido", en M. Revilla (comp.) "Movimientos sociales, acción e identidad", Zona Abierta, $\mathrm{n}^{\circ}$ 69, pp. 181-213.

RUDE, G. (1970), Paris and London in the eighteenth century: studies in popular protest, Viking, Nueva York.

(1971), La multitud en la historia: estudio de los disturbios populares en Francia e Inglaterra, 1730-1848, Siglo XXI, Buenos Aires.

(1981), Revuelta popular y conciencia de clase, Crítica, Barcelona.

(2000), El rostro de la multitud: estudios sobre religión, ideología y protesta popular, Ed. H.J. Kaye, Centro Francisco Tomás y Valiente, Valencia.

SAKWA, R. (1999), Postcommunism, Open University Press, Buckingham.

SCHMITTER, Ph. y W. STREECK (1981), The organization of business interests, Wissenchaftszentrum, Berlin.

SZTOMPKA, P. (1995), Sociología del cambio social, Alianza Ed., Madrid.

TARROW, S. (1995), "Cycles of collective action: between moments of madness and the repertoire of contention", en M. Traugott (ed.), Repertoires and cycles of collective action, Duke University Press, Durham.

(1997), El poder en movimiento. Los movimientos sociales, la acción colectiva y la política, Alianza Ed., Madrid.

(1998), "Social protest and policy reform: May 1968 and the Loi d'Orientation in France", en M.G. Giugni, D. McAdam y Ch. Tilly (eds.), From contention to democracy, Rowman and Littlefield, Lanham. 
RIS

REVISTA INTERNACIONAL DE SOCIOLOGIA

THOMPSON, E. P. (1971), "The moral economy of the English crowd in the eighteenth century", Past and Present, ${ }^{\circ}$ 50, febrero, pp. 76-136.

THRUPP, S. (1970) (ed.), Millennial dreams in action: studies in revolutionary religious movements, Schocken, Nueva York.

TILLY, Ch. (1967), The Vendée: a sociological analysis of the counterrevolution of 1793 , John Wiley, Nueva York.

(1969), "Collective violence in European perspective", en H.D. Graham y T.R. Gurr (eds.), The history of violence in America, Bantam Books, Nueva York.

(1978), From mobilization to revolution, Random House, Nueva York.

(1991), Grandes estructuras, procesos amplios, comparaciones enormes, Alianza Ed., Madrid.

(1995), “Contentious repertoires in Great Britain, 1758-1834”, en M. Traugott (ed.), Repertoires and cycles of collective action, Duke University Press, Durham.

(1997), Roads from past to future, Rowman and Littlefield, Lanham.

(1998), "Conflicto político y cambio social”, en P. Ibarra y B. Tejerina (coords.), Los movimientos sociales: transformaciones politicas y cambio cultural, Ed. Trotta, Madrid.

TOURAINE, A. et al. (1996), Le grand refus: réflexions sur la grève de décembre 1995, Fayard, París.

TURNER, R. y L. KILLIAN (1972), Collective behavior, $2^{\text {a }}$ ed., Prentice-Hall, Englewood Cliffs.

ZALD, M. y J. McCARTHY, Social movements in an organizational society, Transaction, New Brunswick. 